\title{
Expression level of Bcl-XL critically affects sensitivity of hepatocellular carcinoma cells to LIGHT-enhanced and interferon- $\gamma$-induced apoptosis
}

\author{
JUN LI $^{1}$, FENG SHEN ${ }^{1}$, DONG WU ${ }^{1}$, LI-XIN WEI ${ }^{2}$, YI-ZHEN WANG ${ }^{3}$, \\ LE-HUA SHI ${ }^{1}$, YING ZOU ${ }^{4}$ and MENG-CHAO WU ${ }^{1,5}$
}

\begin{abstract}
${ }^{1}$ Division of Comprehensive Treatment, Eastern Hepatobiliary Hospital, ${ }^{2}$ Division of Molecular Oncology, Eastern Hepatobiliary Institute, Second Military Medical University, Shanghai 200438; ${ }^{3}$ Institute of Biochemistry and Cell Biology, Chinese Academy of Sciences, Shanghai 200031; ${ }^{4}$ Division of Dermatology, Changhai Hospital, Second Military Medical University, Shanghai $200433 ;{ }^{5}$ Cell Signal Transduction Laboratory, Eastern Hepatobiliary Institute, Second Military Medical University, Shanghai 200438, P.R. China
\end{abstract}

Received October 26, 2006; Accepted December 20, 2006

\begin{abstract}
The molecular mechanisms of apoptosis caused by IFN- $\gamma$ (interferon gamma)/LIGHT (lymphotoxin-related inducible ligand that competes for glycoprotein $\mathrm{D}$ binding to herpes virus entry mediator on $\mathrm{T}$ cells) have not been studied in detail. The present study was undertaken to gain insights into the signaling pathways involved in apoptosis induced by IFN- $\gamma /$ LIGHT in hepatocellular carcinoma (HCC) cell lines. Cell proliferation assay, flow cytometry, Western blotting, gene transfer and RNA interference were used in this study. LIGHT enhanced IFN- $\boldsymbol{\gamma}$-mediated apoptosis in Hep3B cells. IFN- $\gamma /$ LIGHT-induced apoptosis was inhibited by blocking peptides to the lymphotoxin $\beta$ receptor (LT- $\beta$ R), and not by the herpes virus entry mediator (HVEM). Expression of LT $-\beta$ R remained unchanged after cytokine treatments. IFN- $\gamma /$ LIGHT treatment resulted in the down-regulation of Bcl-XL and the activation of caspase- 9 and caspase- 3 as well as the decrease of phosphorylation of STAT3. HepG2 and SMMC-7721 cells, which showed high levels of endogenous $\mathrm{Bcl}-\mathrm{XL}$, displayed resistance to IFN- $\gamma / \mathrm{LIGHT}$-induced apoptosis. Overexpression of Bcl-XL in Hep3B cells increased the resistance to IFN- $\gamma / \mathrm{LIGHT}$ induced apoptosis while the down-regulation of Bcl-XL in HepG2 and SMMC-7721 cells by RNA interference decreased the resistance. Our study provides important mechanistic insights into IFN- $\gamma /$ LIGHTinduced apoptosis in HCC cells and may help to select better
\end{abstract}

Correspondence to: Dr Feng Shen, Division of Comprehensive Treatment, Eastern Hepatobiliary Hospital, Second Military Medical University, 225 Changhai Road, Shanghai 200438, P.R. China

E-mail: shenfengdfgd@yahoo.com.cn

Key words: Bcl-XL, hepatocellular carcinoma, LIGHT, interferon- $\gamma$, apoptosis therapeutic strategies for certain cancers with distinct Bcl-XL expression.

\section{Introduction}

LIGHT is a new cell surface-bound member of the tumor necrosis factor (TNF) superfamily which participates in multiple biological functions through ligand-receptor signaling. LIGHT induces differentiation of the human rhabdomyosarcoma cell line (RD cells) to smooth muscle cells and stimulates these RD cells to secrete interleukin-8 and RANTES (regulated on activation, normal T cell expressed and secreted) (1). Interestingly, by blocking the activation of both caspase- 3 and caspase-8, LIGHT also acts as an antiapoptotic agent against TNF- $\alpha$-mediated liver injury (2). It has also been proposed that LIGHT is a potent initiator of $\mathrm{T}$ cell co-stimulation signals (3-5) affecting cytotoxic $\mathrm{T}$ lymphocyte (CTL)-mediated tumor rejection (5), allograft rejection (6) and graft versus host disease (7). In addition, an enhanced level of LIGHT may accelerate the progression of acquired immune deficiency syndrome (AIDS) in human immunodeficiency virus (HIV)-infected individuals (8) and promote lipid metabolism, inflammatory response, and thrombus formation in atherosclerotic plaques (9).

LIGHT also enhances interferon- $\gamma($ IFN- $\gamma)$ induced apoptosis (10-12) but the mechanisms remain unclear. LIGHT forms a membrane-anchored homotrimeric complex which is capable of binding to both lymphotoxin $\beta$ receptor (LT- $\beta$ R) and HVEM $(11,12)$. LT- $\beta$ R alone has been found sufficient for the induction of IFN- $\gamma / \mathrm{LIGHT}$-induced apoptosis in HT-29 cells (13), but in MDA-MB-231 human breast carcinoma cells, both HVEM and LT- $\beta$ R are required to achieve the apoptotic effect of IFN- $\gamma /$ LIGHT (12). TR6, a third receptor for LIGHT, suppresses the apoptotic effect of LIGHT and transduces signals from LIGHT to T cells to enhance $\mathrm{T}$ cell proliferation $(14,15)$. Proteins associated with the LIGHT/ LT- $\beta$ R complex have been identified by mass spectrometry, including TNF receptor-associated factors (TRAF) 2 and 3, 
cellular inhibitor of apoptosis protein 1 (cIAP1) and second mitochondria-derived activator of caspase (Smac). Based on this model, the LIGHT/LT- $\beta$ R complex triggers the mitochondria-mediated apoptosis pathway via TRAF3 stimulated release of Smac from mitochondria (16). Overexpression of Bcl-2 also enhances IFN- $\gamma /$ LIGHTmediated apoptosis through Bcl-2 cleavage (17). The Bcl-2 cleavage fragment plays a pro-apoptotic role triggering the apoptosis cascade by a process in which the activation of caspase- 3 is not required. In this study, we utilized hepatocellular carcinoma cells (HCC) to further investigate the antitumor effect of IFN- $\gamma / \mathrm{LIGHT}$ and the possible mechanisms. We demonstrated that the down-regulation of Bcl-XL resulting from the decrease of phosphorylated STAT3 is critical for IFN- $\gamma /$ LIGHT-induced apoptosis, and that HCC cells with high levels of endogenous Bcl-XL are more resistant to IFN- $\gamma /$ LIGHT-induced apoptosis. These findings are in line with previous reports on other tumor cell lines (18-20), suggesting a broad anti-tumor effect of IFN- $\gamma /$ LIGHTinduced cell death in cells with low levels of endogenous Bcl-XL expression.

\section{Materials and methods}

Cell culture and reagents. HCC cell lines Hep3B (21), HepG2 (22) (The American Type Culture Collection, Rockville, MD, USA) and SMMC-7721 cells (23) (The Cell Bank of the Chinese Academy of Sciences, Shanghai, P.R. China) were used in the study. All cells were cultured at $37^{\circ} \mathrm{C}$ in a humidified atmosphere with $5 \% \mathrm{CO}_{2}$ in Dulbecco's modified Eagle's medium (DMEM) and supplemented with $10 \%(\mathrm{v} / \mathrm{v})$ fetal bovine serum (FBS) plus $1 \%$ glutamine (Gibco, Grand Island, NY, USA). A pSuper.neo + EGFP vector was purchased from OligoEngine (Seattle, WA, USA). A recombinant LIGHT soluble protein that only contained the extracellular region of human LIGHT and caspase inhibitors Z-DEVD-fmk, Z-IETD-fmk and Z-LEHD-fmk was purchased from R\&D System (Minneapolis, MN, USA). A recombinant IFN- $\gamma$ protein was obtained from Peprotech (Rocky Hill, NJ, USA). HVEM and LT- $\beta$ R blocking peptide, HVEM, LT- $\beta$ R, STAT3 and pTyrSTAT3 (phosphorylation of ${ }^{705} \mathrm{Tyr}$ ) goat polyclonal antibodies were products of Santa Cruz Biotechnology (CA, USA). Polyclonal antibodies against caspase-3 (only recognizing procaspase-3), caspase- 8 and caspase- 9 (only recognizing procaspase-9), Bcl-XL, Bak and Bid were purchased from Neomark (Fremont, CA, USA). The bicinchoninic acid (BCA) protein assay kit was a product of Pierce Biotechnology (Rockford, IL, USA).

Construction and infection of adenovirus vectors. The human LIGHT overexpressing adenoviral vectors were constructed according to He et al (24). Briefly, cDNA for human LIGHT was inserted into a shuttle vector pAdTrack-CMV following the standard procedures. The resultant plasmid was linearized by enzyme digestion and subsequently co-transfected into $E$. coli BJ5183 with an adenoviral backbone plasmid, pAdEasy-1. Finally, recombinant adenoviruses were propagated on packaging 293 cells and purified by cesium chloride density gradient centrifugation and subsequent dialysis. The recombinant adenovirus carrying full LIGHT cDNA was defined as Ad-LIGHT and the mock recombinant adenovirus was named Ad. HCC cells were plated in 6- or 24-well plates, and adenoviral infection was performed the next day for $4 \mathrm{~h}$ with the virus diluted in DMEM to desired multiplicity of infection (MOI).

Construction of plasmid vectors and generation of stable transfectants. The double-stranded DNA template encoding small interfering RNAs (siRNAs) for STAT3 (25) and Bcl-XL (26) was synthesized. The sequences were STAT3: 5'GATC CCCGCAGCAGCTGAACAACATGTTCAAGAGACATG TTGTTCAGCTGCTGCTTTTTA-3' (forward), 5'AGC TTAAAAAGCAGCAGCTGAACAACATGTCTCTTGAAC ATGTTGTTCAGCTGCTGCGGG-3' (reverse); Bcl-XL: 5'GATCCCCCAGGGACAGCATATCAGAGTTCAAGAG ACTCTGATATGCTGTCCCTGTTTTTA-3' (forward), 5'AGCTTAAAAACAGGGACAGCATATCAGAGTCTCTT GAACTCTGATATGCTGTCCCTGGGG-3' (reverse). The pSuper.neo-EGFP vector, in which short hairpin RNAs (shRNA) are expressed under the control of the $\mathrm{H} 1$ promoter, was constructed according to Gao et al (25). The negative control vector that expresses a hairpin siRNA with limited homology to any known sequences in the human genome was provided with the vector kit. The cDNA encoding full-length human Bcl-XL was cloned into pIRES2-EGFP (Clontech, Mountain View, CA, USA). pIRES2-EGFP was used as a mock vector.

All vectors mentioned above were transfected into $\mathrm{HCC}$ cells using LipofectAMINE ${ }^{\mathrm{TM}} 2000$ (Invitrogen, Carlsbad, CA, USA) according to the manufacturer's instructions. Stably transfected cells were selected with $800 \mathrm{ng} / \mathrm{ml} \mathrm{G} 418$ (Sigma, St. Louis, MO, USA), followed by confirmation with Western blott analysis.

Cell viability assay. Cell viability was determined by MTT quantitative colorimetric assay. The cells were seeded in 96-well plates. After different treatments, $20 \mu 15 \mathrm{mg} / \mathrm{ml} \mathrm{3-}$ (4, 5-dimethylthiazol-2-yl)-2, 5-diphenyltetrazolium bromide (MTT) was added to each well and the plates were incubated at $37^{\circ} \mathrm{C}$ for $4 \mathrm{~h}$. The cells were then lysed by the addition of $150 \mu 1$ dimethyl sulfoxide (DMSO) per well and mixed with a microplate shaker for approximately $5 \mathrm{~min}$. The optical density of each sample was determined by measuring the absorbance at $492 \mathrm{~nm}$ versus $650 \mathrm{~nm}$ using an enzyme linked immunosorbent assay reader (BioRad, Hercules, CA, USA).

Membrane receptors and LIGHT analysis. Cells were harvested and incubated with Abs for HVEM, LT- 3 R or LIGHT at $10 \mu \mathrm{g} / \mathrm{ml}$ in binding buffer at $4^{\circ} \mathrm{C}$ for $30 \mathrm{~min}$, followed by one wash and staining with phycoerythrin conjugated bovine anti-goat IgG at a final concentration of $20 \mu \mathrm{g} / \mathrm{ml}$. The cell surface fluorescence intensity was analyzed by FACScan flow cytometry (BD Biosciences, San Jose, CA, USA).

Analysis of apoptosis. The extent of apoptosis was evaluated by the Annexin V/propidium iodide (PI) method. Briefly, $1 \times 10^{6}$ cells from each treatment group were incubated with Annexin V-FITC solution (R\&D System) at $4^{\circ} \mathrm{C}$ for $10 \mathrm{~min}$ and washed three times with cold phosphate buffered saline (PBS) and then stained with PI at room temperature for $10 \mathrm{~min}$. 
A

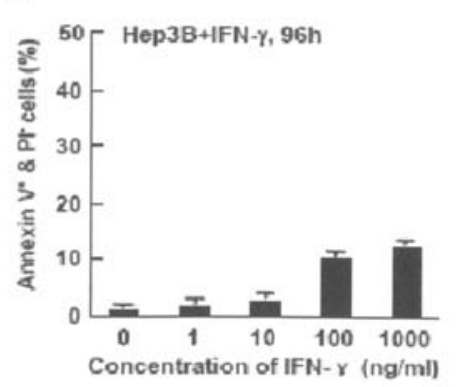

C

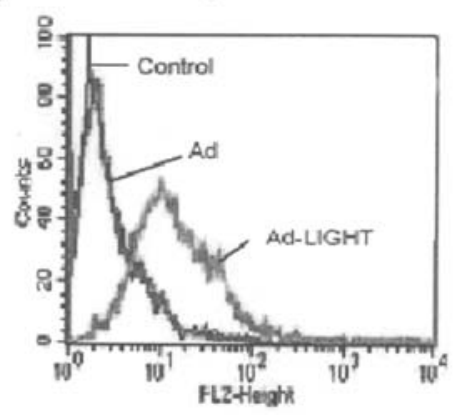

$E$

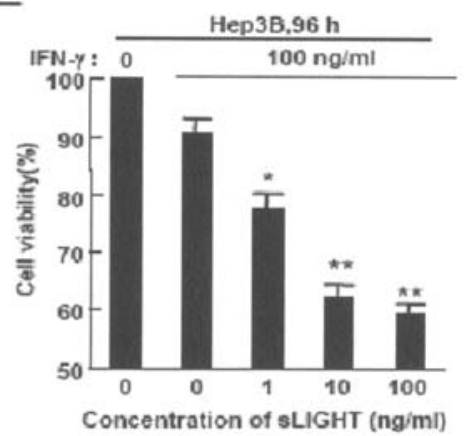

G

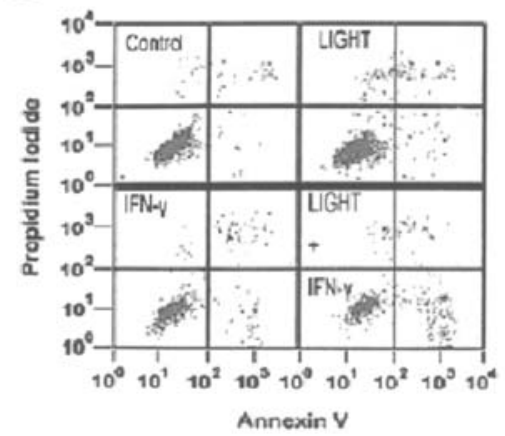

$\mathrm{B}$

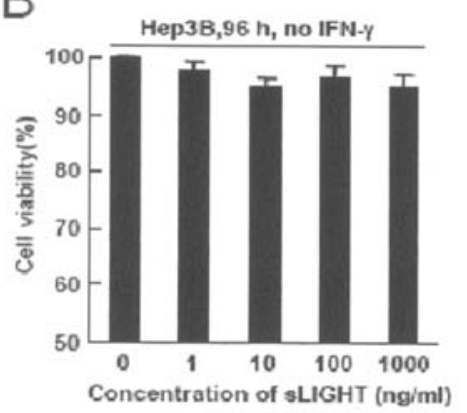

$\square$

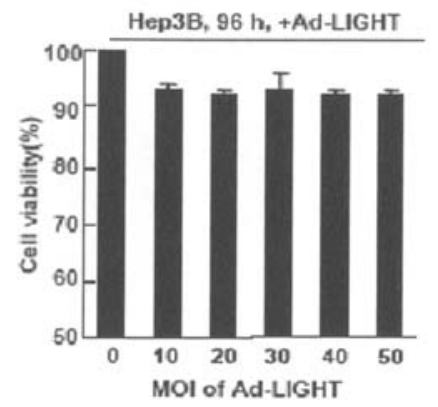

F
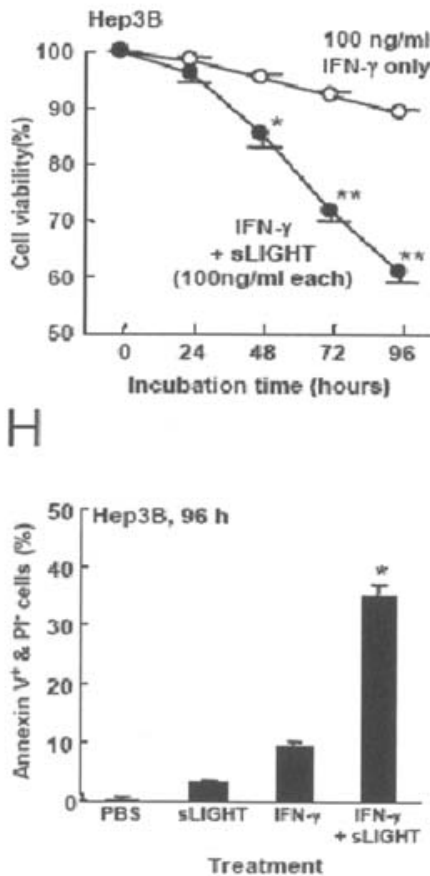

Figure 1. LIGHT enhances the apoptosis of Hep3B cells induced by IFN- $\gamma$. (A) Hep3B cells were treated with IFN- $\gamma(0,1,10,100$ and $1000 \mathrm{ng} / \mathrm{ml})$ and the percentage of cell apoptosis was analyzed by Annexin V/PI staining. The experiments were performed in triplicate and in at least two separate experiments. The bar indicates the standard error. (B) Hep3B cells were treated with sLIGHT $(0,1,10,100$ and $1000 \mathrm{ng} / \mathrm{ml}$ ) and cell viability was determined at $96 \mathrm{~h}$ by MTT assay. The mean number of viable cells in the $0 \mathrm{ng} / \mathrm{ml}$ group was set as $100 \%$ and the relative viability of other samples was calculated accordingly. The experiments were performed in triplicate and in at least two separated experiments. The bar indicates the standard error. (C) Hep3B cells were infected with adenovirus expressing full-length human LIGHT cDNA (Ad-LIGHT) or vector virus carrying no transgene (Ad). Cells positive for LIGHT expression on the plasma membrane were marked with goat anti-human LIGHT polyclonal Ab and identified by flow cytometry. Uninfected cells were used as the control. (D) Hep3B cells were infected with Ad-LIGHT at 10 to 50 multiplicity of infectivity (MOI) for $24 \mathrm{~h}$ and further cultured for $96 \mathrm{~h}$. Cell viability was determined. The mean number of viable cells in the untreated group was set as $100 \%$ and the relative viability of other samples was calculated accordingly. The experiments were performed in triplicate and in at least two separate experiments. The bar indicates the standard error. (E) Hep3B cells were incubated with IFN- $\gamma$ $(100 \mathrm{ng} / \mathrm{ml})$ and different concentrations of LIGHT $(0,1,10$ and $100 \mathrm{ng} / \mathrm{ml})$ for $96 \mathrm{~h}$. Cell viability was determined. (F) Hep3B cells were incubated with IFN- $\gamma$ $(100 \mathrm{ng} / \mathrm{ml})$ alone $(\circ)$ or IFN- $\gamma(100 \mathrm{ng} / \mathrm{ml})$ plus LIGHT $(100 \mathrm{ng} / \mathrm{ml})(\bullet)$ for 24, 48, 72, or $96 \mathrm{~h}$. Cell viability was determined at each time-point. "p $<0.05$; ${ }^{* *} \mathrm{p}<0.01$, versus group treated with IFN- $\gamma(100 \mathrm{ng} / \mathrm{ml})$ alone $(\mathrm{E})$ and versus group treated with IFN- $\gamma(100 \mathrm{ng} / \mathrm{ml})$ alone at each time point $(\mathrm{F})$. (G, H) Hep3B cells were incubated with either phosphate buffered saline (PBS), or LIGHT protein (100 ng/ml) alone, or IFN- $\gamma(100 \mathrm{ng} / \mathrm{ml})$ alone, or LIGHT (100 ng/ml) plus IFN- $\gamma(100 \mathrm{ng} / \mathrm{ml})$ for $96 \mathrm{~h}$. Cell apoptosis was analyzed by Annexin V/PI staining. The percentage of apoptotic (Annexin-positive and PI-negative) cells in each group is plotted in $\mathrm{G}$. The numbers shown in $\mathrm{H}$ are mean values of three independent experiments. ${ }^{p} \mathrm{p}<0.05$, versus group treated with IFN- $\gamma(100 \mathrm{ng} / \mathrm{ml})$ alone. 
A
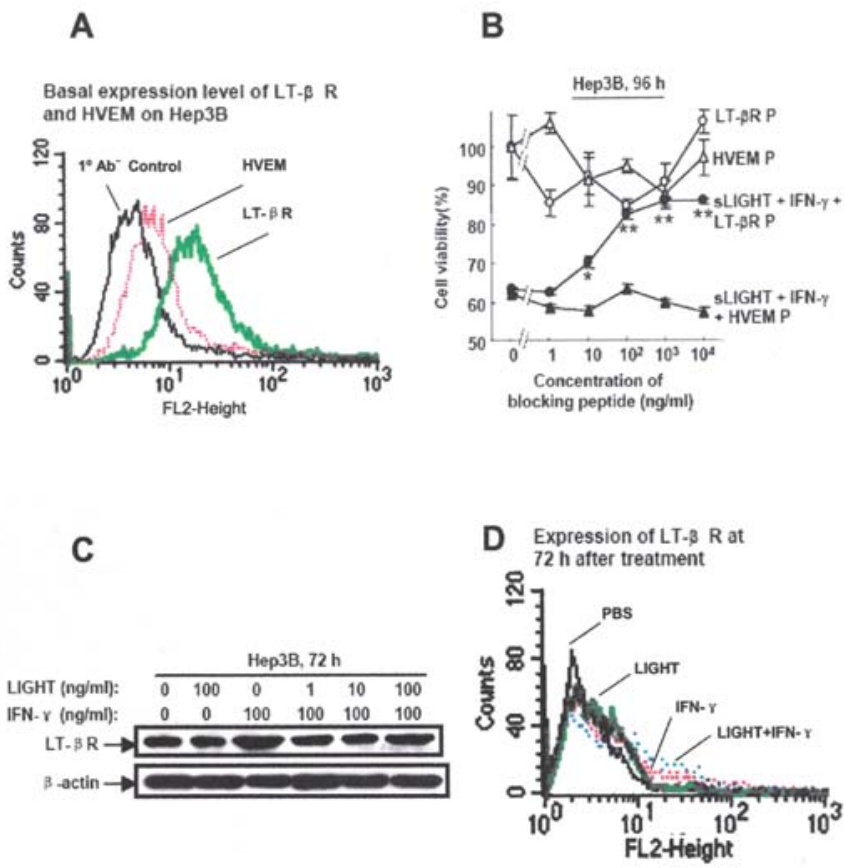

Figure 2. Expression of LT- $\beta$ R and HVEM on Hep3B cells and their participation in IFN- $\gamma /$ LIGHT treatment. (A) Hep3B cells were stained with goat polyclonal antibody against HVEM or LT- $\beta$ R and the expression level of each receptor was determined by flow cytometry. Cells treated solely with secondary antibodies were used as an unstained negative control. (B) Hep3B cells were incubated either with various doses of HVEM blocking peptide alone (HVEM P), LT- $\beta$ R blocking peptide alone (LT- $\beta$ R P), or sLIGHT $(100 \mathrm{ng} / \mathrm{ml})$ plus IFN- $\gamma(100 \mathrm{ng} / \mathrm{ml})$ in the presence of various amounts of HVEM P or LT-ß R P for $96 \mathrm{~h}$. The viability of treated cells was then determined. The mean number of viable cells in untreated Hep3B was set as $100 \%$ and the relative viability of other samples was calculated accordingly. The experiments were performed in triplicate, and in at least two separate experiments. The bar indicates the standard error. " $\mathrm{p}<0.05$; ${ }^{* *} \mathrm{p}<0.01$, versus group treated with sLIGHT $(100 \mathrm{ng} / \mathrm{ml})$ plus IFN- $\gamma$ $(100 \mathrm{ng} / \mathrm{ml})$ without the blocking peptide. (C) Hep3B cells were treated with various concentrations of LIGHT and/or IFN- $\gamma$ (as indicated) for $72 \mathrm{~h}$. Cell lysates were prepared and Western blotting was performed to determine the expression level of LT- $\beta$ R in all treatments. $\beta$-actin was used as an internal control for total protein loading. (D) Hep3B cells were treated with LIGHT $(100 \mathrm{ng} / \mathrm{ml})$ and $/$ or IFN- $\gamma(100 \mathrm{ng} / \mathrm{ml})$ for $72 \mathrm{~h}$. Then cells were stained with goat polyclonal antibody against LT- $\beta$ R, and the receptor expression level was determined by FACS analysis. Cells treated with PBS were used as negative controls.

The fluorescence intensity of Annexin V-FITC and PI of individual cells was analyzed by FACScan.

Western blott analysis. Cells were treated with various compounds and lysed for $30 \mathrm{~min}$ at $4^{\circ} \mathrm{C}$ in lysis buffer. Protein concentration was measured spectrophotometrically using the BCA protein assay. Equal amounts of proteins were subjected to SDS-PAGE electrophoresis and transferred onto nitrocellulose membranes (Hybond, Amersham Pharmacia Biotech, Freiburg, Germany). After blocking with Tris buffered saline (TBS) containing 5\% skim milk and $0.5 \%$ Tween-20, the membranes were reacted with appropriate antibodies (1:1000 for LT-B R, 1:800 for HVEM, 1:400 for Bcl-XL, Bak, Bid, caspase-3, caspase-8, and caspase-9, 1:800 for STAT3 and 1:400 for pTrySTAT3) in TBS containing 3\% bovine serum albumin and $0.2 \%$ Tween-20. After 3 washes, blots were incubated with horseradish peroxidase-conjugated secondary antibodies for $60 \mathrm{~min}$ and developed with enhanced chemiluminescence reagents (Santa Cruz Biotechnology), followed by exposure to X-ray film (Kodak, Rochester, NY, USA).

Statistical analysis. Student's t-test was used to analyze the differences between groups as mentioned in the figure legends. A p-value of $<0.05$ was considered statistically significant.

\section{Results}

LIGHT enhances IFN- $\gamma$-mediated apoptosis of Hep3B cells. IFN- $\gamma$ alone induced a moderate dose-dependent increase of apoptosis of Hep3B cells (Fig. 1A). Therefore, a single concentration of $100 \mathrm{ng} / \mathrm{ml}$ of IFN- $\gamma$ was chosen for the rest of this study. As with IFN- $\gamma$, LIGHT alone in the form of the recombinant soluble protein (sLIGHT) or the full-length protein expressed by transfecting an adenovirus vector carrying the full-length cDNA insertion of human LIGHT protein (AdLIGHT) did not significantly induce apoptosis of Hep3B cells (Fig. 1B, C and D).

When Hep3B cells were treated with SLIGHT and IFN- $\gamma$ together, significant decrease in cell viability was observed (Fig. 1E and F). After 96-h incubation, IFN- $\gamma$ plus 1, 10 and $100 \mathrm{ng} / \mathrm{ml}$ sLIGHT significantly reduced Hep3B cell viability to $77.5 \%, 63.8 \%$ and $59.7 \%$, respectively (Fig. 1E). This effect was also time dependent. After the treatment with IFN- $\gamma$ alone, the cell viability decreased gradually over time to $\sim 90 \%$ at $96 \mathrm{~h}$, whereas after the treatment with IFN- $\gamma$ and sLIGHT $(100 \mathrm{ng} / \mathrm{ml}$ each) together, the viability changed slightly after $24 \mathrm{~h}$, decreased to $85.5 \%$ at $48 \mathrm{~h}$ and reduced significantly to $71.3 \%$ and $60.6 \%$ at $72 \mathrm{~h}$ and $96 \mathrm{~h}$ respectively (Fig. 1F).

Analysis of cells with Annexin V/PI staining demonstrated that the observed cell death in these treatments was apoptotic rather than necrotic (Fig. 1G). The treatment with sLIGHT (at $100 \mathrm{ng} / \mathrm{ml}$ ) or IFN- $\gamma$ alone produced only $3.3 \%$ or $9.4 \%$ apoptotic cells respectively after $96-\mathrm{h}$ incubation while the treatment with both cytokines produced markedly increased apoptotic cells (35.6\%) (Fig. 1H).

LT- $\beta$ R, but not HVEM, participates in IFN- $\gamma / L I G H T$ induced apoptosis of Hep $3 B$ cells. LIGHT interacts with two receptors, HVEM and LT- $\beta$ R. Both receptors were identified as being expressed by Hep3B cells by FACS analysis (Fig. 2A).

In order to identify which receptor was involved in the cytotoxic effect of IFN- $\gamma /$ LIGHT in Hep3B cells, soluble HVEM and LT- $\beta$ R blocking peptides were added to the cell culture to investigate whether IFN- $\gamma /$ LIGHT-induced apoptosis could be reversed (Fig. 2B). The HVEM or LT- $\beta$ R blocking peptide alone showed no affect on cell death. However, the LT- $\beta$ R blocking peptide, but not HVEM, demonstrated a dose-dependent effect of blocking the IFN- $\gamma /$ LIGHT-induced apoptosis of Hep3B cells. The effect of LT- $\beta$ R blocking peptide was significant at $10 \mathrm{ng} / \mathrm{ml}$ and the cell viability increased by $>80 \%$ when the peptide concentration was $>100 \mathrm{ng} / \mathrm{ml}$. However, the LT- $\beta$ R blocking peptide failed to completely recover the cell viability of IFN- $\gamma /$ LIGHT-treated Hep3B cells to the level of the untreated control group $(86 \%)$, even at a concentration of up to $1 \times 10^{4} \mathrm{ng} / \mathrm{ml}$. 
A

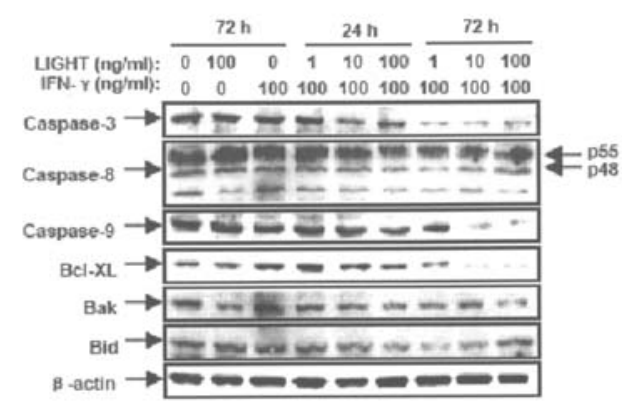

B

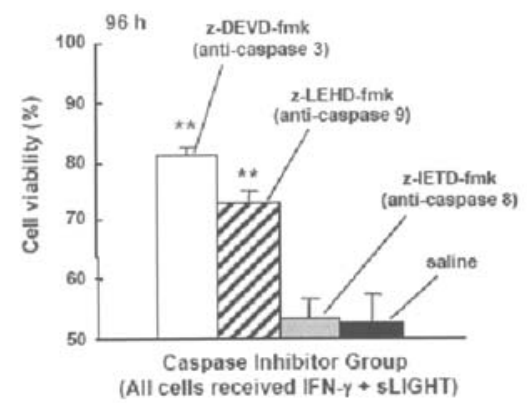

Figure 3. Expression levels of caspase-3, caspase-8, caspase-9, Bcl-XL, Bak and Bid in Hep3B cells treated with IFN- $\gamma /$ LIGHT. (A) Hep3B cells were treated with $100 \mathrm{ng} / \mathrm{ml} \mathrm{IFN-} \gamma$ and various concentrations of LIGHT for $24 \mathrm{~h}$ or $72 \mathrm{~h}$ as indicated. Cell lysates containing $30 \mu \mathrm{g}$ of protein were subjected to $12 \%$ Tris-glycine gel electrophoresis followed by Western blotting with rabbit polyclonal antibodies against caspase-3, caspase- 8 , caspase-9, Bcl$\mathrm{XL}$, Bak, Bid, respectively. Cells treated with $100 \mathrm{ng} / \mathrm{ml} \mathrm{IFN-} \gamma$ or $100 \mathrm{ng} / \mathrm{ml}$ LIGHT alone and untreated cells were used as the controls. $B$-actin was used as an internal control for total protein loading. (B) Hep3B cells $\left(2 \times 10^{5}\right)$ treated with $100 \mathrm{ng} / \mathrm{ml} \mathrm{sLIGHT}$ and $100 \mathrm{ng} / \mathrm{ml}$ of IFN- $\gamma$ were also incubated with $100 \mu \mathrm{M}$ of caspase-3 inhibitor Z-DEVD-fmk, caspase-9 inhibitor ZIEHD-fmk, caspase-8 inhibitor Z-IEHD-fmk, or normal saline for $96 \mathrm{~h}$. Cell viability was then measured. The viability of untreated (without any cytokine and inhibitor) cells was set at $100 \%$, and the relative viability of other samples was calculated accordingly. The experiments were performed in triplicate, and in at least two separated experiments. The bar indicates the standard error. ${ }^{* *} \mathrm{p}<0.01$, versus group treated with normal saline.

The expression levels of LT- $\beta$ R before and after the treatment with LIGHT and/or IFN- $\gamma$ were examined by Western blotting and flow cytometry, and were found unchanged under all treatments (Fig. 2C and D).

Alterations of apoptosis cascade components. Little is known about the signal transduction pathway of IFN- $\gamma / \mathrm{LIGHT}$-induced apoptosis. In order to explore this mechanism in HCC cells, alterations of a series of apoptosis cascade components were examined.

The protein levels of apoptosis initiator caspase-9 (involved in mitochondria pathway), apoptosis effector caspase-3, as well as anti-apoptotic protein Bcl-XL, were found diminished $24 \mathrm{~h}$ to $72 \mathrm{~h}$ after the combined treatment with LIGHT and IFN- $\gamma$, and the levels of the two caspases did not change after the treatment with either LIGHT or IFN- $\gamma$ alone. On the other hand, the protein levels of apoptosis initiator caspase- 8 (involved in the death receptor pathway), and Bcl-2 family members, Bak and Bid, remained largely constant after all treatments (Fig. 3A).
A

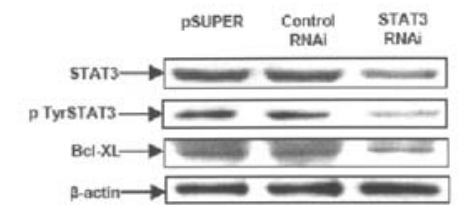

B

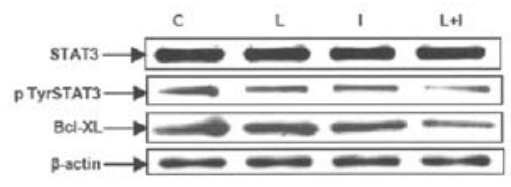

Figure 4. IFN- $\gamma /$ LIGHT may down-regulate Bcl-XL through the decrease of pTyrSTAT3 in Hep3B cells. (A) Hep3B cells were transfected with pSUPER plasmid, the plasmid carrying STAT3 specific siRNA, or the plasmid carrying scrambled control siRNA, and stable clones were selected. Western blott analysis was used to examine the levels of Bcl-XL in different cells. Expression of $B$-actin is shown to indicate equal total protein loading. (B) Hep3B cells were treated with $100 \mathrm{ng} / \mathrm{ml} \mathrm{IFN-} \gamma$ and LIGHT for $72 \mathrm{~h}$ $(\mathrm{L}+\mathrm{I})$ as indicated. Cell lysates containing $30 \mu \mathrm{g}$ protein were subjected to $10 \%$ Tris-glycine gel electrophoresis followed by Western blott assay with goat polyclonal antibodies against STAT3, pTyrSTAT3, and Bcl-XL, respectively. Cells treated with $100 \mathrm{ng} / \mathrm{ml} \mathrm{IFN- \gamma}$ (I) or $100 \mathrm{ng} / \mathrm{ml} \mathrm{LIGHT}$ (L) alone and untreated cells (C) were used as the controls. B-actin was used as an internal control for total protein loading.

The function of caspases was further confirmed by the inhibitory experiment. IFN- $\gamma / \mathrm{LIGHT}$-induced apoptosis was significantly reversed by caspase-3 inhibitor Z-DEVD-fmk and caspase-9 inhibitor Z-LEHD-fmk but not by caspase- 8 inhibitor Z-IETD-fmk (Fig. 3B). This observation was consistent with the Western blott analysis which showed that caspase-3 and caspase-9, but not caspase-8, were involved in IFN- $\gamma /$ LIGHT-induced apoptosis of Hep3B cells (Fig. 3A).

The down-regulation of $B c l-X L$ is attributed to the decrease of pTyrSTAT3 induced by IFN- $\gamma /$ LIGHT. STAT3 has been shown to participate in oncogenesis through the upregulation of genes encoding apoptosis inhibitors, such as $\mathrm{Bcl-XL}$, in some cancer cell lines (27). To assess the relationship between the down-regulation of Bcl-XL and the decrease of pTyr STAT3, Hep3B cells were transfected with STAT3 specific siRNA. Results showed that the expression and phosphorylation of STAT3 were significantly decreased in the cells transfected with a plasmid carrying STAT3 specific siRNA compared with mock-transfected cells and in cells transfected with the plasmid carrying negative control siRNA. Correspondingly, Bcl-XL was significantly reduced in Hep3B cells transfected with STAT3 specific siRNA compared with the controls (Fig. 4A). These data indicate that the decrease of pTyrSTAT3 may lead to the downregulation of $\mathrm{Bcl}-\mathrm{XL}$ in Hep3B cells.

In order to confirm that the down-regulation of Bcl-XL induced by IFN- $\gamma /$ LIGHT is the result of the decrease of STAT3 phosphorylation, alterations of STAT3 or the phosphorylation of STAT3 were examined after Hep3B cells were treated with LIGHT and/or IFN- $\gamma$. The level of STAT3 remained unchanged in all treatment groups. However, the pTyrSTAT3 and Bcl-XL diminished after the combined 
A

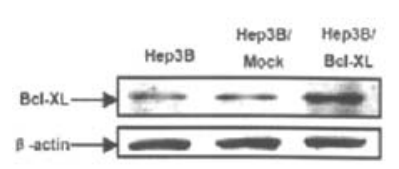

B

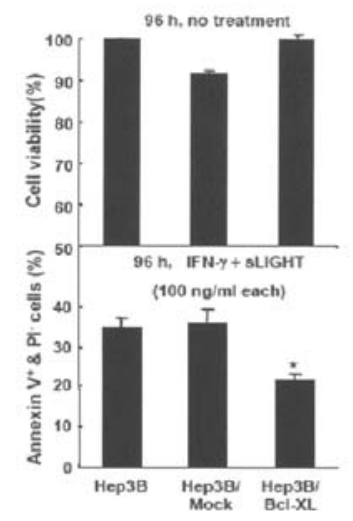

C

$96 \mathrm{~h}$, all cells treated with $100 \mathrm{ng} / \mathrm{ml}$ IFN $-\gamma+100 \mathrm{ng} / \mathrm{ml}$ sLIGHT
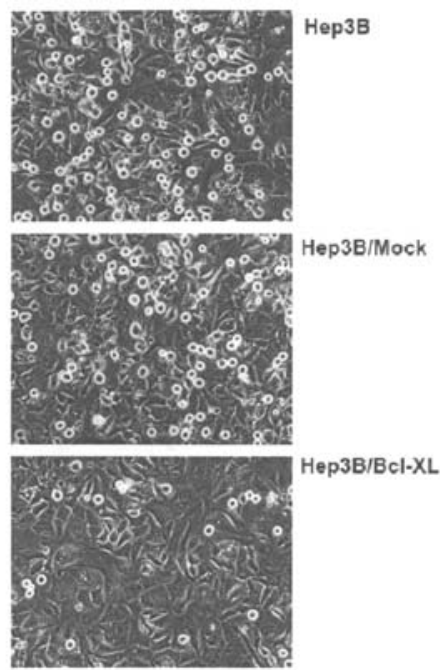

A

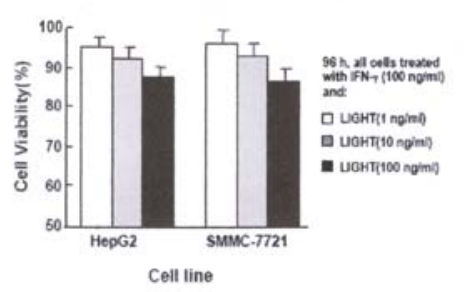

C

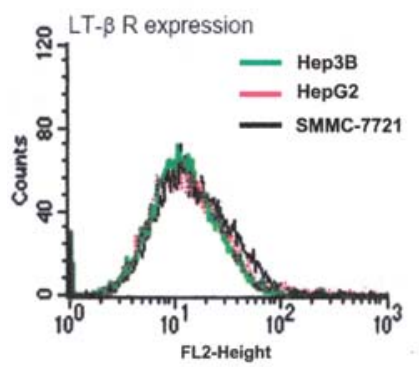

B

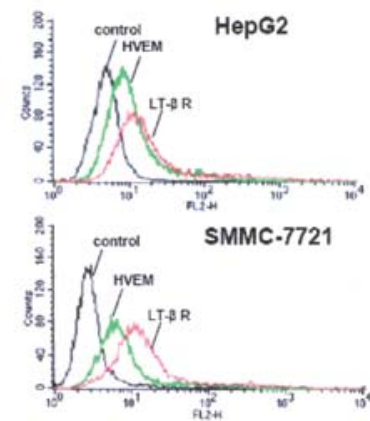

D

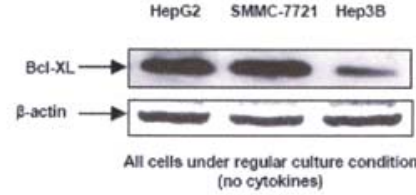

Figure 5. Overexpression of Bcl-XL reduces IFN- $\gamma /$ LIGHT-induced apoptosis in Hep3B cells. (A) Cell lysates (containing $30 \mu \mathrm{g}$ of total protein) from Hep3B, Hep3B/mock and Hep3B/Bcl-XL cells (without any treatment) were subjected to $12 \%$ Tris-glycine gel electrophoresis followed by Western blott assay with goat polyclonal antibodies against Bcl-XL or B-actin. Expression of $B$-actin is shown to indicate equal total protein loading. (B) Cell viability was determined after Hep3B, Hep3B/mock, or Hep3B/Bcl-XL cells were cultured for $96 \mathrm{~h}$ (without any treatment). The mean number of parental Hep3B cells was set at $100 \%$. The experiments were performed in triplicate, and in at least two separate experiments. The bar indicates the standard error. (C) Hep3B, Hep3B/mock, or Hep3B/Bcl-XL cells were incubated with IFN- $\gamma(100 \mathrm{ng} / \mathrm{ml})$ and sLIGHT $(100 \mathrm{ng} / \mathrm{ml})$ for $96 \mathrm{~h}$. Apoptosis was then analyzed by Annexin V/PI staining. The percentage of apoptotic cells was plotted. The numbers were mean values of three independent experiments. * $p<0.05$, versus Hep3B group. (D) Cell morphology under the conditions as described in $\mathrm{C}$ was photographed under an optic microscope ( $\mathrm{x} 40)$.

treatment with LIGHT and IFN- $\gamma$ for $72 \mathrm{~h}$, but not after the treatment with LIGHT or IFN- $\gamma$ alone (Fig. 4B).

Overexpression of Bcl-XL increased resistance of Hep $3 B$ cells to IFN- $\gamma /$ LIGHT-induced apoptosis. To further test the role of Bcl-XL in IFN- $\gamma /$ LIGHT-induced apoptosis of human HCC cells, a Hep3B derived cell line stably expressing Bcl-XL (Hep3B/Bcl-XL) was established. Overexpression of Bcl-XL in Hep3B/Bcl-XL cells was confirmed by Western blott analysis (Fig. 5A). Untreated Hep3B/Bcl-XL cells grew at a similar rate to Hep3B cells or Hep3B mock transfected cells (Hep3B/Mock) (Fig. 5B). When treated with IFN- $\gamma /$ LIGHT $(100 \mathrm{ng} / \mathrm{ml}$ each) for $96 \mathrm{~h}$, approximately $35 \%$ of parental Hep3B or Hep3B/mock cells underwent apoptosis, whereas only approximately $20 \%$ of Hep3B/Bcl-XL cells underwent apoptosis (Fig. 5C), suggesting that overexpression of $\mathrm{Bcl}-\mathrm{XL}$ reduced the sensitivity of Hep3B cells to IFN- $\gamma /$ LIGHTinduced apoptosis. Cell morphological changes also supported the finding that overexpression of Bcl-XL inhibited IFN- $\gamma /$ LIGHT-induced apoptosis of Hep3B cells (Fig. 5D).

HepG2 and SMMC-7721 cells are more resistant to LIGHT/ IFN- $\gamma$-induced apoptosis and have higher expression of Bcl-XL. To determine whether LIGHT/IFN- $\gamma$ induces apoptosis of

Figure 6. Resistance of HepG2 and SMMC-7721 cells to IFN- $\gamma / \mathrm{LIGHT}$ induces apoptosis and high endogenous expression of Bcl-XL. (A) HepG2 and SMMC-7721 cells were treated with IFN- $\gamma(100 \mathrm{ng} / \mathrm{ml})$ and sLIGHT (1, 10 , and $100 \mathrm{ng} / \mathrm{ml}$ ) for $96 \mathrm{~h}$, and cell viability was assayed. Viability of untreated control cells was set at $100 \%$, and viability relative to the control was presented. The experiments were performed in triplicate, and in at least two separate experiments. The bar indicates the standard error. (B) HepG2 and SMMC-7721 cells were stained with goat polyclonal antibodies against HVEM and LT- $\beta$ R, and the expression level of each receptor was then determined by FACS analysis. Cells treated solely with secondary antibodies were used as an unstained negative control. (C) Hep3B, HepG2 and SMMC7721 cells were stained with a goat polyclonal antibody against LT- $\beta$ R and the receptor expression level was then determined by FACS analysis. (D) Western blott analysis was performed on cell lysates from HepG2, SMMC7721 and Hep3B cells with a goat polyclonal antibody against Bcl-XL. Expression of $\beta$-actin is shown to indicate equal total protein loading.

other HCC cell lines, HepG2 and SMMC-7721 cells were cultured with IFN- $\gamma(100 \mathrm{ng} / \mathrm{ml})$ and sLIGHT $(1,10$ and $100 \mathrm{ng} / \mathrm{ml}$ ) for $96 \mathrm{~h}$. At the end of the culture, however, only approximately $12 \%$ of the cells were found dead after the dual cytokine treatment at the highest concentration (Fig. 6A), which was significantly less than the percentage of IFN- $\gamma /$ LIGHT-induced cell death in Hep3B cells (up to $\sim 40 \%$ ) (Fig. 1E). Thus, HepG2 and SMMC-7721 appeared to have lower susceptibility to IFN- $\gamma /$ LIGHT-induced apoptosis. To investigate whether this was due to overexpression of $\mathrm{Bcl}-\mathrm{XL}$, the levels of Bcl-XL protein in HepG2 and SMMC7721 were evaluated by Western blotting and the results showed that these two cell lines contained much higher levels of Bcl-XL protein than Hep3B cells under the normal culture condition (Fig. 6D). In contrast, both HepG2 and SMMC-7721 cells expressed HVEM and LT-B R (Fig. 6B), and no difference was observed in the level of LT- $\beta$ R expression among Hep3B, HepG2, and SMMC-7721 cells (Fig. 6C).

Down-regulation of Bcl-XL level via specific siRNA sensitizes HepG2 and SMMC-7721 cells to IFN- $\gamma / L I G H T$ - 
A

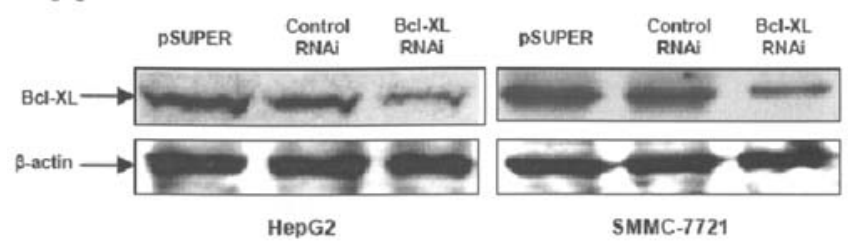

B

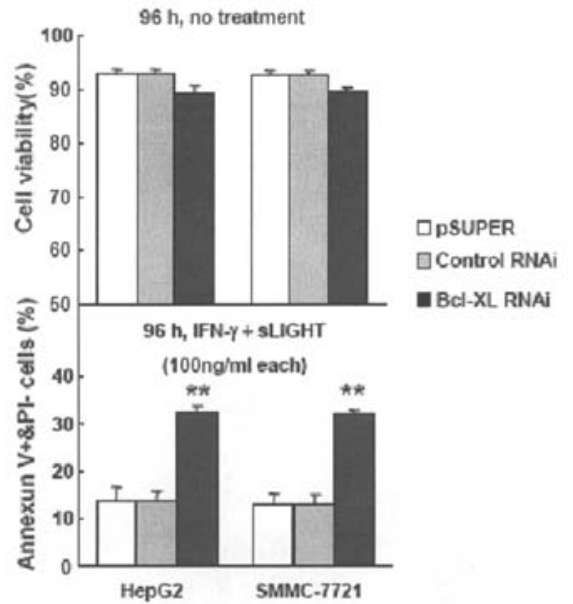

Figure 7. Down-regulation of Bcl-XL through specific siRNA increases the susceptibility of HepG2 and SMMC-7721 cells to IFN- $\gamma /$ LIGHT-induced apoptosis. (A) HepG2 and SMMC-7721 cells were transfected with pSUPER plasmid, the plasmid carrying Bcl-XL specific siRNA, or the plasmid carrying scrambled control siRNA, and stable clones were selected. Western blott analysis was used to examine the level of Bcl-XL in different cells. Expression of $\beta$-actin is shown to indicate equal total protein loading. (B) Cell viability was determined after cells described in A were cultured for $96 \mathrm{~h}$ without treatment. Untransfected parental cells were used as the controls for $100 \%$ viability. (C) Cells described in A were incubated with IFN- $\gamma(100 \mathrm{ng} / \mathrm{ml})$ and sLIGHT $(100 \mathrm{ng} / \mathrm{ml})$ for $96 \mathrm{~h}$. Apoptosis was analyzed by Annexin V/PI staining. The percentage of apoptotic cells was plotted. The numbers are mean values of three independent experiments. ${ }^{* *} \mathrm{p}<0.01$, versus HepG2 or SMMC-7721 group.

induced apoptosis. To further assess the relationship between overexpression of $\mathrm{Bcl}-\mathrm{XL}$ and the resistance of $\mathrm{HepG} 2$ and SMMC-7721 cells to IFN- $\gamma /$ LIGHT-induced apoptosis, the Bcl-XL gene expression in these two cell lines was stably reduced by specific siRNA and the effect of IFN- $\gamma / \mathrm{LIGHT}$ treatment was re-evaluated.

The Bcl-XL protein levels in HepG2 and SMMC-7721 cells, stably transfected with a plasmid expressing Bcl-XL specific siRNA were significantly lower than those in cells transfected with a backbone plasmid or a plasmid carrying scrambled control siRNA (Fig. 7A). A slight reduction in cell viability $(\sim 7 \%)$ without cytokine treatment was observed in Bcl-XL specific siRNA transfected cells compared with the mock or control siRNA transfected cells (Fig. 7B). With IFN- $\gamma /$ LIGHT dual cytokine treatment however, a dramatic increase of cell apoptosis was observed in both HepG2 and SMMC-7721 cells stably expressing Bcl-XL specific siRNA, compared with the mock or control siRNA transfected cells ( $\sim 32 \%$ in Bcl-XL siRNA groups vs $\sim 13 \%$ in controls) (Fig. 7C).

\section{Discussion}

In the present study, we found that cytokine LIGHT enhanced IFN- $\gamma$-mediated apoptosis of cells in a human HCC cell line, Hep3B. However, in other HCC cell lines with high levels of endogenous Bcl-XL such as HepG2 and SMMC-7721, IFN$\gamma /$ LIGHT failed to show a significant cytotoxicity effect. Hep3B cells gained more resistance to IFN- $\gamma /$ LIGHTinduced apoptosis by overexpressing $\mathrm{Bcl}-\mathrm{XL}$ protein while HepG2 and SMMC-7721 cells became more susceptible to IFN- $\gamma /$ LIGHT-induced apoptosis by knocking-down Bcl-XL protein expression. IFN- $\gamma /$ LIGHT-induced apoptosis in Hep3B cells involved LIGHT receptor LT-B R, but not HVEM. The activation of caspase-9 and caspase-3, but not caspase-8, and the decrease of phosphorylation of STAT3 resulted in the down-regulation of Bcl-XL expression which appeared to be the most critical factor in IFN- $\gamma /$ LIGHTinduced apoptosis.

The fact that neither LIGHT nor IFN- $\gamma$ alone induced significant apoptosis in Hep3B cells, and that the combined treatment with these two cytokines induced a marked apoptotic effect indicated that the enhancement of IFN- $\gamma$ mediated apoptosis in Hep3B cells by LIGHT is probably a synergistic effect. However the mechanisms by which LIGHT synergizes with IFN- $\gamma$ and $\mathrm{Bcl}-\mathrm{XL}$ is down-regulated remain unclear. A previous study reported that LIGHT or IFN- $\gamma$ / LIGHT induced lower intercellular adhesion molecule-1 (ICAM-1) expression in a STAT1-deficient fibrosarcoma cell line U3A than in 2fTGH fibrosarcoma cells (28). However, when U3A1-1 cells were STAT1 reconstituted, the LIGHTinduced ICAM-1 expression pattern was restored to a similar level as in $2 \mathrm{fTGH}$ (28). IFN- $\gamma$ is known to induce the activation of JAK1 and JAK2 and subsequent activation of STAT1. STAT1 then induces the expression of the pro-apoptotic IRF-1 protein, which mediates apoptosis (29). Thus, LIGHT may enhance IFN- $\gamma$-mediated apoptosis through enhancing the activation of the STAT1 signaling pathway. Interestingly, STAT3 is another transcription factor which is up-regulated during IFN- $\gamma$ treatment, and the activated STAT1 and STAT3 inhibit each other (30). STAT3 has also been shown to be decreased after IFN- $\gamma /$ LIGHT treatment. It is possible that IFN- $\gamma /$ LIGHT activates STAT1 synergistically, which then inhibits STAT3 activation and down-regulates the expression of Bcl-XL in HCC cells. Further studies are ongoing in our laboratories to examine this hypothesis as well as the related signal transduction interactions.

Although accumulating evidence shows that STAT3 contributes to oncogenesis by upregulating Bcl-XL, the NF$\kappa \mathrm{B}$ signaling pathway is also an important pathway to elevate the expression of Bcl-XL (31) and to prolong cell survival (32). The down-regulation of Bcl-XL mediated by IFN- $\gamma /$ LIGHT may result from a decreased activity of $N F-\kappa B$. Previous studies have shown that the suppression of NF- $\kappa \mathrm{B}$ activation by IFN- $\gamma$ contributes to HT-29 cell death induced by IFN- $\gamma /$ LIGHT (18). It has also been shown that STAT3 and NF-кB act with each other to regulate the expression of the target gene. For example, during the formation of the STAT3 complex, NF-кB p65 is essential for the synergistic induction of the serum amyloid A (SAA) by IL-1+IL-6 stimulation (33). Thus, it is possible that there is a crosstalk between the 
STAT3 and NF-кB pathway in the down-regulation of Bcl-XL induced by IFN- $\gamma /$ LIGHT.

LT- $\beta$ R appears to be the receptor involved in LIGHT enhancement of the IFN- $\gamma$-mediated apoptosis in Hep3B cells, since in this study, only the LT- $\beta$ R blocking peptide, and not the HVEM blocking peptide, reversed the apoptosis induced by IFN- $\gamma /$ LIGHT although both HVEM and LT-B R were expressed in Hep3B cells. Studies on LIGHT receptors have shown a large diversity of their biological functions. A previous study reported that a prostatic adenocarcinoma cell line PC- 3 which expresses LT- $\beta$ R but not HVEM was resistant to LIGHT-mediated cytotoxicity (12). However, in HT29 cells, LT-ß R was found to be necessary and sufficient for apoptosis induced by LIGHT (13), which is consistent with our findings. In this study, a high dose of LT- $\beta$ R blocking peptide did not completely block the apoptosis induced by IFN- $\gamma /$ LIGHT, probably because the LT- $\beta$ R blocking peptide only inhibited the activity of LIGHT, but not that of IFN- $\gamma$. However, it is also possible that receptors other than LT- $\beta \mathrm{R}$ may interact with LIGHT and transduce an apoptotic signal.

Death receptor, mitochondria and endoplasmic are the three major apoptotic pathways which have been identified so far $(34,35)$. IFN- $\gamma /$ LIGHT-induced apoptosis of HCC cells involves the mitochondria pathway, as shown by the activation of caspase-9 and the down-regulation of Bcl-XL in our study. On the other hand, caspase-8, an initiator of the death receptor pathway, showed no alteration in the apoptosis of HCC cells induced by IFN- $\gamma /$ LIGHT. In addition, LIGHT cannot bind to the death receptor, and the cytoplasmic domain of LT- $\beta$ R does not contain consensus sequences homologous to the death domain. A previous study demonstrated that IFN- $\gamma$ alone induced a slight activation of caspase- 8 in A549 cells (36), which is consistent with our observation in Hep3B cells. Based on these findings, we conclude that IFN- $\gamma /$ LIGHT may not transduce the apoptotic signal through the death receptor in Hep3B cells. It was also observed in our study that caspase- 3 and -9 inhibitors did not inhibit the apoptosis completely. Aden et al (22) and Chen et al (37) proposed that a caspase-independent apoptosis pathway might exist through which reactive oxygen species (ROS) and other inducers could bypass the alteration of caspases.

Bcl-XL has been shown to antagonize apoptosis induced by various stimuli and play a strong protective role against apoptosis, thus it facilitates tumor formation, progression and resistance to therapies (38). In our study, Bcl-XL was downregulated during apoptosis induced by LIGHT and IFN- $\gamma$ in Hep3B cells. Enforced overexpression of Bcl-XL in Hep3B cells increased the resistance to IFN- $\gamma / \mathrm{LIGHT}$. Moreover, a higher endogenous Bcl-XL level contributed to the resistance of HepG2 and SMMC-7721 cells to the apoptosis induced by LIGHT and IFN- $\gamma$, and the artificial knocking down of Bcl$\mathrm{XL}$ expression in these two cell lines by RNA interference recovered the susceptibility to the dual cytokine treatment. We hence conclude that Bcl-XL plays a central and counteractive role in the apoptosis of HCC cells induced by IFN- $\gamma$ / LIGHT.

Of clinical relevance, $\mathrm{Bcl}-\mathrm{XL}$ is overexpressed in one-third of human HCC tissues and may function as an important apoptosis antagonist during tumor growth in vivo (39). Therefore, analysis of Bcl-XL expression may identify patients who are less likely to benefit from IFN- $\gamma /$ LIGHT treatment but may be candidates suitable for alternative strategies such as blocking the activity of Bcl-XL.

In conclusion, LIGHT enhances IFN- $\gamma$-induced apoptosis of HCC cells in which Bcl-XL plays a central and counteractive role. Bcl-XL overexpression inhibits IFN- $\gamma / \mathrm{LIGHT}$-induced apoptosis in Hep3B cells which have low levels of endogenous $\mathrm{Bcl}-\mathrm{XL}$, while Bcl-XL specific siRNA restores the sensitivity to IFN- $\gamma /$ LIGHT treatment of HepG2 and SMMC-7721 cells which have high levels of endogenous Bcl-XL. These data provide important mechanistic insights into IFN- $\gamma /$ LIGHTinduced apoptosis in HCC cells, and may help to select better therapeutic strategies for certain cancers with a distinct Bcl-XL expression.

\section{Acknowledgements}

This study was supported by grants from the National Natural Science Foundation of China (project no. 30171051 and 30540068), and the Dawn Foundation of Shanghai (project no. 02 SG30).

\section{References}

1. Hikichi Y, Matsui H, Tsuji I, Nishi K, Yamada T, Shintani Y and Onda H: LIGHT, a member of the TNF superfamily, induces morphological changes and delays proliferation in the human rhabdomyosarcoma cell line RD. Biochem Biophys Res Commun 289: 670-677, 2001.

2. Matsui H, Hikichi Y, Tsuji I, Yamada T and Shintani Y: LIGHT, a member of the tumor necrosis factor ligand superfamily, prevents tumor necrosis factor-alpha-mediated human primary hepatocyte apoptosis, but not Fas-mediated apoptosis. J Biol Chem 277: 50054-50061, 2002

3. Scheu S, Alferink J, Potzel T, Barchet W, Kalinke U and Pfeffer K: Targeted disruption of LIGHT causes defects in costimulatory $\mathrm{T}$ cell activation and reveals cooperation with lymphotoxin beta in mesenteric lymph node genesis. J Exp Med 195: 1613-1624, 2002.

4. Tamada K, Shimozaki K, Chapoval AI, Zhai Y, Su J, Chen SF, Hsieh SL, et al: LIGHT, a TNF-like molecule, costimulates T cell proliferation and is required for dendritic cell-mediated allogeneic T cell response. J Immunol 164: 4105-4110, 2000.

5. Tamada K, Shimozaki K, Chapoval AI, Zhu G, Sica G, Flies D, Boone T, et al: Modulation of T-cell-mediated immunity in tumor and graft-versus-host disease models through the LIGHT co-stimulatory pathway. Nat Med 6: 283-289, 2000.

6. Ye Q, Fraser CC, Gao W, Wang L, Busfield SJ, Wang C, Qiu Y, et al: Modulation of LIGHT-HVEM costimulation prolongs cardiac allograft survival. J Exp Med 195: 795-800, 2002.

7. Tamada K, Tamura H, Flies D, Fu YX, Celis E, Pease LR, Blazar BR, et al: Blockade of LIGHT/LTbeta and CD40 signaling induces allospecific $\mathrm{T}$ cell anergy, preventing graftversus-host disease. J Clin Invest 109: 549-557, 2002.

8. Lama $\mathbf{J}$ and Ware CF: Human immunodeficiency virus type 1 Nef mediates sustained membrane expression of tumor necrosis factor and the related cytokine LIGHT on activated T cells. J Virol 74: 9396-9402, 2000.

9. Scholz H, Sandberg W, Damas JK, Smith C, Andreassen AK, Gullestad L, Frøland SS, et al: Enhanced plasma levels of LIGHT in unstable angina: possible pathogenic role in foam cell formation and thrombosis. Circulation 112: 2121-2129, 2005.

10. Harrop JA, McDonnell PC, Brigham-Burke M, Lyn SD, Minton J, Tan KB, Dede K, et al: Herpesvirus entry mediator ligand (HVEM-L), a novel ligand for HVEM/TR2, stimulates proliferation of T cells and inhibits HT29 cell growth. J Biol Chem 273: 27548-27556, 1998.

11. Mauri DN, Ebner R, Montgomery RI, Kochel KD, Cheung TC, Yu GL, Ruben S, et al: LIGHT, a new member of the TNF superfamily, and lymphotoxin alpha are ligands for herpesvirus entry mediator. Immunity 8: 21-30, 1998. 
12. Zhai Y, Guo R, Hsu TL, Yu GL, Ni J, Kwon BS, Jiang GW, et al: LIGHT, a novel ligand for lymphotoxin beta receptor and TR2/HVEM induces apoptosis and suppresses in vivo tumor formation via gene transfer. J Clin Invest 102: 1142-1151, 1998.

13. Rooney IA, Butrovich KD, Glass AA, Borboroglu S, Benedict CA, Whitbeck JC, Cohen GH, et al: The lymphotoxinbeta receptor is necessary and sufficient for LIGHT-mediated apoptosis of tumor cells. J Biol Chem 275: 14307-14315, 2000.

14. Shi G, Luo H, Wan X, Salcedo TW, Zhang J and Wu J: Mouse $\mathrm{T}$ cells receive costimulatory signals from LIGHT, a TNF family member. Blood 100: 3279-3286, 2002.

15. Yu KY, Kwon B, Ni J, Zhai Y, Ebner R and Kwon BS: A newly identified member of tumor necrosis factor receptor superfamily (TR6) suppresses LIGHT-mediated apoptosis. J Biol Chem 274: 13733-13736, 1999.

16. Kuai J, Nickbarg E, Wooters J, Qiu Y, Wang J and Lin LL: Endogenous association of TRAF2, TRAF3, cIAP1, and Smac with lymphotoxin beta receptor reveals a novel mechanism of apoptosis. J Biol Chem 278: 14363-14369, 2003.

17. Chen MC, Hsu TL, Luh TY and Hsieh SL: Overexpression of bcl-2 enhances LIGHT- and interferon-gamma-mediated apoptosis in Hep3BT2 cells. J Biol Chem 275: 38794-38801, 2000.

18. Chang YH, Chao Y, Hsieh SL and Lin WW: Mechanism of LIGHT/interferon-gamma-induced cell death in HT-29 cells. J Cell Biochem 93: 1188-1202, 2004.

19. Zhang M, Guo R, Zhai Y and Yang D: LIGHT sensitizes IFNgamma-mediated apoptosis of MDA-MB-231 breast cancer cells leading to down-regulation of anti-apoptosis Bcl-2 family members. Cancer Lett 195: 201-210, 2003.

20. Zhang MC, Liu HP, Demchik LL, Zhai YF and Yang da J: LIGHT sensitizes IFN-gamma-mediated apoptosis of HT-29 human carcinoma cells through both death receptor and mitochondria pathways. Cell Res 14: 117-124, 2004.

21. Knowles BB, Howe CC and Aden DP: Human hepatocellular carcinoma cell lines secrete the major plasma proteins and hepatitis B surface antigen. Science 209: 497-499, 1980.

22. Aden DP, Fogel A, Plotkin S, Damjanov I and Knowles BB: Controlled synthesis of HBsAg in a differentiated human liver carcinoma-derived cell line. Nature 282: 615-616, 1979.

23. Tong R, Zhou R and Lu F: The establishment and primary biological characteristics of human hepatoma SMMC-7721 cell line. J 2nd Milit Med Univ 1: 5-9, 1980.

24. He TC, Zhou S, da Costa LT, Yu J, Kinzler KW and Vogelstein B: A simplified system for generating recombinant adenoviruses. Proc Natl Acad Sci USA 95: 2509-2514, 1998.
25. Gao LF, Xu DQ, Wen LJ, Zhang XY, Shao YT and Zhao XJ: Inhibition of STAT3 expression by siRNA suppresses growth and induces apoptosis in laryngeal cancer cells. Chung Kuo Yao Li Hsueh Pao 26: 377-383, 2005.

26. Lei XY, Zhong M, Feng LF, Yan CY, Zhu BY, Tang SS and Liao DF: Silencing of Bcl-XL expression in human MGC-803 gastric cancer cells by siRNA. Acta Biochim Biophys Sin 37 $555-560,2005$.

27. Buettner R, Mora LB and Jove R: Activated STAT signaling in human tumors provides novel molecular targets for therapeutic intervention. Clin Cancer Res 8: 945-954, 2002.

28. Zhang M, Guo R, Zhai Y, Fu XY and Yang D: Light stimulates IFNgamma-mediated intercellular adhesion molecule-1 upregulation of cancer cells. Hum Immunol 64: 416-426, 2003.

29. Schroder K, Hertzog PJ, Ravasi T and Hume DA: Interferongamma: an overview of signals, mechanisms and functions. $\mathrm{J}$ Leukoc Biol 75: 163-189, 2004.

30. Hong F, Jaruga B, Kim WH, Radaeva S, El-Assal ON, Tian Z, Nguyen VA, et al: Opposing roles of STAT1 and STAT3 in T cell-mediated hepatitis: regulation by SOCS. J Clin Invest 110: 1503-1513, 2002.

31. Chen C, Edelstein LC and Gelinas C: The Rel/NF-kappaB family directly activates expression of the apoptosis inhibitor Bcl-xL. Mol Cell Biol 20: 2687-2695, 2000.

32. Perkins ND: The Rel/NF-kappa B family: friend and foe. Trends Biochem Sci 25: 434-440, 2000.

33. Hagihara K, Nishikawa T, Sugamata Y, Song J, Isobe T, Taga T and Yoshizaki K: Essential role of STAT3 in cytokine-driven NF-кB-mediated serum amyloid: a gene expression. Genes Cells 10: 1051-1063, 2005.

34. Daniel PT: Dissecting the pathways to death. Leukemia 14: 2035-2044, 2000.

35. Green DR and Reed JC: Mitochondrial and apoptosis. Science 281: 1309-1312, 1998.

36. Park SY, Seol JW, Lee YJ, Cho JH, Kang HS, Kim IS, Park SH, et al: IFN-gamma enhances TRAIL-induced apoptosis through IRF-1. Eur J Biochem 271: 4222-4228, 2004

37. Chen MC, Hwang MJ, Chou YC, Chen WH, Cheng G, Nakano H, Luh TY, et al: The role of apoptosis signal-regulating kinase 1 in lymphotoxin-beta receptor-mediated cell death. J Biol Chem 278: 16073-16081, 2003

38. Kim R: Unknotting the roles of Bcl-2 and $\mathrm{Bcl}-\mathrm{xL}$ in cell death. Biochem Biophys Res Commun 333: 336-343, 2005.

39. Tetsuo T, Liu X, Fujimoto J, Friedman SL and Takahashi H: Expression and role of Bcl-XL in human hepatocellular carcinomas. Hepatology 34: 55-61, 2001. 